Article

\title{
Inclusiveness of Contract Farming along the Modern Food Supply Chain: Empirical Evidence from Taiwan
}

\author{
Yir-Hueih Luh $\mathbb{D}$ \\ Department of Agricultural Economics, National Taiwan University, Taipei City 10617, Taiwan; \\ yirhueihluh@ntu.edu.tw; Tel.: +(886)-2-3366-2651
}

Received: 20 April 2020; Accepted: 22 May 2020; Published: 24 May 2020

check for updates

\begin{abstract}
One of the debates in the literature of contract farming concerns contracting firms' preferences over large growers and if contract farming is inclusive of smallholders. The empirical evidence was mixed, which may be due to ignoring the stylized fact that modern food supply chain is characterized by large organized retailers who often contract with farmers. The present study aims at addressing this issue by incorporating sales to supermarket and hypermarket chains as one of the determinants of contract farming participation. Based on a nationally-representative farm household data set in Taiwan, this study presents empirical evidence to support the positive effects of selling farm produce to supermarkets and/or hypermarkets on the probability of contract farming participation. However, the increase in the share of chain stores, convenience stores, as well as local grocers was found to lower the probability of contract farming participation. The results suggest the effect of organized retailing on the participation of contract farming varies with different food retailers in the modern supply chain. Moreover, based on the predicted probability from the participation-determining model, contracting firms in Taiwan are found to exhibit preferences towards large-scale growers. A further analysis of the interaction between grower's scale and membership of farmer organizations indicates participation in the farmer organizations can effectively mitigate contracting firms' scale bias. The significance of the moderating effect of farmer organizations suggests their important role in the inclusion of smallholders into modern food supply chain.
\end{abstract}

Keywords: contract farming; food supply chain; organized retailing; super/hyper markets; farmer organization membership; inclusive food policies

\section{Introduction}

One of the debates in the literature of contract farming concerns if contracting firms prefer mediumand large-scale growers over the small-scale ones [1-10]. The empirical evidence based on if production scale, often measured by landholding, positively affected contract farming participation, has been mixed. The mixed results in the literature may be due to ignoring one important determinant of the farm household's participation in contract farming-supplying farm produce to supermarkets and hypermarkets. The present study aims at addressing this issue using a nationally-representative data set in Taiwan to answer the question: Is contract farming inclusive of smallholders along the modern food supply chain characterized by large organized retailers?

Contract farming is a viable means to link smallholders to the retail market, which thereby increases smallholders' income and improves their welfare. There is a considerable body of research exploring the determinants of the smallholder's participation in contract farming. Most of the previous studies on the determinants of participation in contract farming focused on socio-economic factors including characteristics of farmers, farm households, and farms. For instance, in the investigation of factors driving contract farming participation in Northern Vietnam, it was found that farm operators with higher educational level and larger physical asset holdings have a higher probability to participate 
in formal contract farming [3]. Similarly, a study of Indian farm households found farmers who participated in contract farming in general hold higher educational level, and possess more of the productive assets and market access opportunities [5]. From the perspective of small-scale farmers in South Africa, it was found that land size and the share of off-farm income in the total income were the major determinants for the participation in contract farming, which suggested small-scale farmers were more likely to be excluded from contracting [6]. The observation that participation in contract farming is biased towards larger growers was further confirmed by finding that the size of the farm is one of the major factors deterring Ghana crop farmers' participation in contract farming [8]. Summarizing from the previous literature, the reasons to support contracting firms' preferences over large growers are lower production costs associated with economies of scale [10], lower transaction costs [11], lower probability of producer default [12], and lower occurrence of contract violations [13].

On the other hand, there existed some previous studies finding no significant empirical evidence in support of contracting firms' preferences over large growers but rather the inclusion of small farmers into the modern food supply chain $[4,9,10,14,15]$. For instance, in the study of Indonesia, the inclusiveness of contract farming was found for boiler producers but not for corn growers, which was possibly due to the fact that large-scale irrigated land is necessary for participation in crop contracting [10]. In addition to the socio-economic factors that affect the intensity of contract farming, smallholders in a south state of India were found to allocate more of land and family labor to contract crop [15]. As an example of recent research into determinants of contract farming, factors influencing alternative contractual arrangements was investigated for the Vietnamese rice sector [9]. Results in that study indicated that smaller farmers are more inclined to participate in contract farming in an attempt to secure higher levels of buyer investment.

The mixed results in the literature suggest basing the conclusion on if landholding is a significant and positive factor for contract farming participation may lead to biased inference due to omitting one important determinant-supplying farm produce to supermarkets and hypermarkets. Contract farming is "an agreement between farmers and processing and/or marketing firms for the production and supply of agricultural products under forward agreements" (p. 2, [16]), the choice of contract farming participation is actually determined by both the preferences of the growers and that of the contracting firms which has been typically ignored in the past. Although contracting firms' preferences are not observable, supplying part of the farm produce to the supermarkets and hypermarkets is a reasonable indication since the two organized retailers are the major contracting firms in the modern food supply chain. By incorporating sales to supermarket and hypermarket chains as one of the determinants of contract farming participation, this study proposes an improved identification strategy tackling the issue as to whether contract farming is inclusive of the smallholders or not, which thereby makes a significant contribution to the existing body of research.

This study focuses on three marketing options related to farm household's choice of contract farming in Taiwan. The three marketing options include supermarkets/hypermarkets, other retailers and government and farmer organizations. The association of the first two marketing options and contract farming is based on the literature of organized retailing $[4,17,18]$. As opposed to traditional retailers, organized retailers are the modern retailer chains having multi-format outlets, including supermarkets, hypermarkets, and convenience stores [19-22]. However, in most recent studies on organized retailing, the notion is referred to as supermarkets in particular [23]. The development of supermarkets, hypermarkets, and convenience stores in Taiwan is portrayed in Figure 1. The first mass merchandising store (hypermarket) in Taiwan, Makro, was established in 1989. Since then, hypermarkets have become one of the important consumption outlets for Taiwanese consumers in addition to traditional markets, convenience stores, and supermarkets. The three types of organized retailers took similar market shares in the 1990s. During the past two decades of development, convenience stores took the largest share and hypermarkets ranked the second. Considering the prevalence of the three food retailing outlets in Taiwan, this study differentiates organized retailing outlets into two categories including supermarkets/hypermarkets as well as other retailers which 
comprises convenience stores and chain stores. By doing so, this study adds to the literature through the examination of the linkage between modern food retailing outlets and contract farming from a broader perspective, which thus provides a more comprehensive delineation of the relationship between the two income determinants.

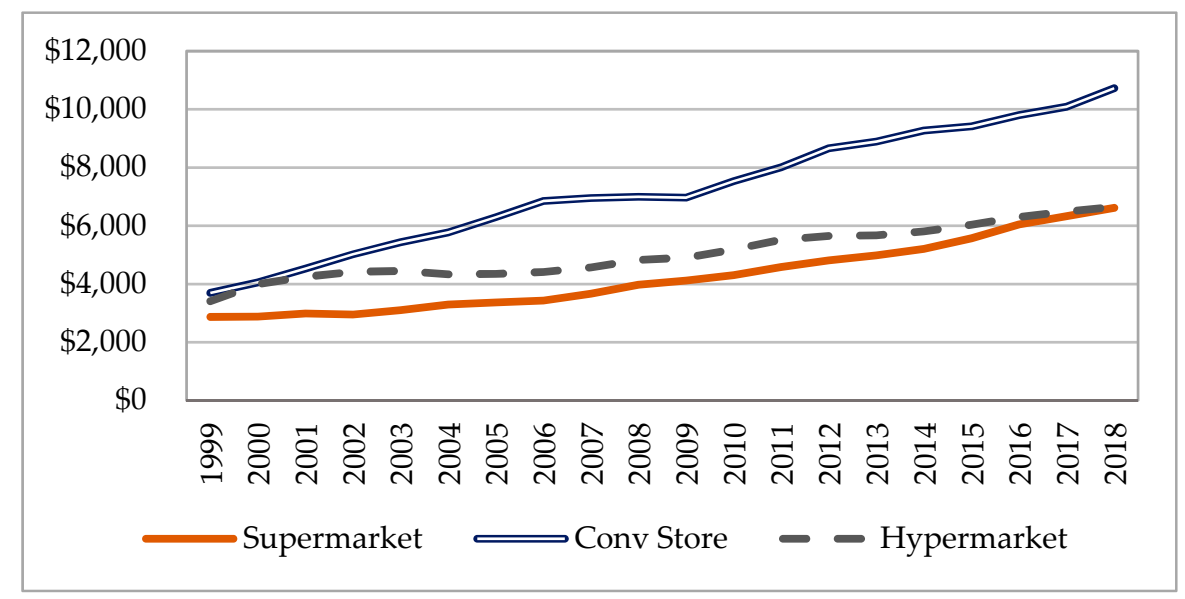

Figure 1. Sales volume of organized retailers (unit: million USD).

\section{Materials and Methods}

A theoretical model to link the contracting firm's preferences to contract farming participation is presented, followed by the empirical model of contract farming participation. Using the shares of farm produce supplied to different retailers as a proxy of the contracting firm's preferences, the empirical model is composed of a system of equations including the principal operator's contract farming participation decision and choice of marketing shares. Taking into account possible problem of selection bias resulting from the correlation across equations, the system of equations is estimated simultaneously to yield consistent estimates.

\subsection{Data Source}

The farm household data used in this study is taken from the 2013 Primary Farm Household Survey (PFHS). The primary farm households are those with an annual income of more than 200,000 NTD (around \$6500) and at least one member under 65 years old working on the farm. The survey targeted at the population of 150,000 farm households satisfying the designated qualifications, and randomly selected 10,000 samples using the stratified random sampling method.

The descriptive statistics of the PFHS are listed in Table 1. Among the 9951 farm households, $6 \%$ sells farm produce to organized retailers. Share of sales to supermarkets and hypermarkets, other retailers, and farmer organizations and government are, respectively, $0.45 \%, 2.1 \%$, and $11.23 \%$. About $4 \%$ of the farm households participated in contract farming. Most of the farm operators are male, with an average age of 57, an educational level lower than senior high, and approximately 29 years of farming experience. About half of the farm operators were unemployed before entering the agriculture business. The landholding is generally small with on average five workers on the farm. In the PFHS, almost $80 \%$ of the farm households is in the central and southern area in Taiwan, and most of the sample is composed of crop farms. 


\subsection{Theoretical Framework}

Following the existing body of research on the farming practice and technology adoption behavior [24-27], the theoretical model of the farmer's participation in contract farming starts with the expected profit maximization problem as follows:

$$
\begin{array}{lrl}
\max _{y_{n}, y_{c}, \phi_{n} \geq 0, \phi_{c} \geq 0} E[\pi] & =p_{n} y_{n}+p_{c} y_{c}-\mathbf{w}^{T} \mathbf{v}\left(\phi_{n}(\mathrm{HK}, \mathbf{z}), \phi_{c}(\mathrm{HK}, \mathbf{z}, R)\right)+A \\
\text { s.t. } & y_{n} & =f_{n}\left(v\left(\phi_{n}(\mathrm{HK}, \mathbf{z})\right), \phi_{n}(\mathrm{HK}, \mathbf{z})\right) \\
y_{c} & =f_{c}\left(v\left(\phi_{c}(\mathrm{HK}, \mathbf{z}, R)\right), \phi_{c}(\mathrm{HK}, \mathbf{z}, R)\right)
\end{array}
$$

In Equation (1), subscript $n$ and $c$ denote non-contract and contract products, and $p_{n}, p_{c}, y_{n}$, and $y_{c}$ are respectively the price and output of non-contract and contract products. Exogenous income such as government transfer payment is denoted by $A$. The vectors of unit price and amount of variable input are denoted by $\mathbf{w}$ and $\mathbf{v}\left(\phi_{n}(),. \phi_{c}().\right)$. Employment of the variable input is a function of the share of farmland used in producing contract or noncontract products, $\phi_{i}().(i=n, c)$, which is a function of human capital (HK), the vector of the farm and farm households' socio-economic characteristics $(\mathbf{z})$,

\begin{tabular}{|c|c|c|c|}
\hline Variable & Definition & Mean & S.D. \\
\hline Contract & Participation in contract farming, $1=$ yes, $0=$ no & 0.04 & 0.2 \\
\hline Super/hyper markets & Share of sales to supermarkets and hypermarkets (\%) & 0.45 & 5.91 \\
\hline Other retailers & Share of sales to chain/convenience stores, grocers $(\%)$ & 2.1 & 11.93 \\
\hline Govt and farmer org & Share of sales to government and farmer organizations (\%) & 11.23 & 28.16 \\
\hline Gender & Gender of principal farm operator, $1=$ male, $0=$ female & 0.89 & 0.31 \\
\hline Age & Age of principal farm operator (years) & 57.27 & 10.9 \\
\hline Farm experience & Farm experience of principal operator (years) & 29.28 & 14.7 \\
\hline Elementary and below & Education: Elementary school or below, $1=$ yes, $0=$ no & 0.38 & 0.49 \\
\hline Junior high & Education: junior high school, $1=$ yes, $0=$ no & 0.27 & 0.45 \\
\hline Senior high & Education: senior high school, $1=$ yes, $0=$ no & 0.29 & 0.45 \\
\hline College and up & Education: college or above, $1=$ yes, $0=$ no & 0.06 & 0.24 \\
\hline Agriculture & Previous work: agriculture employee, $1=$ yes, $0=$ no & 0.06 & 0.24 \\
\hline Non-agriculture & Previous work: non-agriculture industry, $1=$ yes, $0=$ no & 0.37 & 0.48 \\
\hline Self-employed & Previous work: self-employed, $1=$ yes, $0=$ no & 0.1 & 0.3 \\
\hline Unemployed & Previous work: none, $1=$ yes, $0=$ no & 0.47 & 0.5 \\
\hline On-farm work days & Principal Operator's days of work on farm (annual base) & 237.13 & 70.02 \\
\hline PROD-MKTG team & Member of production-marketing team, $1=$ yes, $0=$ no & 0.36 & 0.48 \\
\hline Agri. cooperatives & Member of agricultural cooperatives, $1=$ yes, $0=$ no & 0.05 & 0.23 \\
\hline Farmer org & Member of at least one farmer organizations, $1=$ yes, $0=$ no & 0.85 & 0.36 \\
\hline Total labor & Total labor (persons) & 5.16 & 5.24 \\
\hline Farm land & Farm land (hectares) & 0.94 & 1.03 \\
\hline Crop & Type of operation: crop growers, $1=$ yes, $0=$ no & 0.96 & 0.19 \\
\hline Livestock & Type of operation: livestock growers, $1=$ yes, $0=$ no & 0.07 & 0.25 \\
\hline Food Processor & Type of operation: food processor, $1=$ yes, $0=$ no & 0.04 & 0.2 \\
\hline Leisure farm & Type of operation: leisure farm, $1=$ yes, $0=$ no & 0.01 & 0.1 \\
\hline Rice & Major crop: rice, $1=$ yes, $0=$ no & 0.12 & 0.32 \\
\hline Vegetable & Major crop: vegetables, $1=$ yes, $0=$ no & 0.27 & 0.45 \\
\hline Fruit & Major crop: fruits, $1=$ yes, $0=$ no & 0.42 & 0.49 \\
\hline Specialty & Major crop: specialty crops, $1=$ yes, $0=$ no & 0.06 & 0.24 \\
\hline Other crops & Major crop: other crops, $1=$ yes, $0=$ no & 0.07 & 0.25 \\
\hline Certification & At least one of the food safety certificates, $1=$ yes, $0=$ no & 0.13 & 0.33 \\
\hline North & Location: northern area, $1=$ yes, $0=$ no & 0.12 & 0.32 \\
\hline Central & Location: central area, $1=$ yes, $0=$ no & 0.48 & 0.5 \\
\hline South & Location: southern area, $1=$ yes, $0=$ no & 0.33 & 0.47 \\
\hline East & Location: eastern area, $1=$ yes, $0=$ no & 0.07 & 0.26 \\
\hline
\end{tabular}
and retailer's preference $(R)$ if used in contract produce.

Table 1. Variable definition and descriptive statistics. 
The reason for contract and non-contract products to have different production function is due to the fact that contracting firms may have intensive input regimen [15], higher quality requirements [16] or high probability to switch from staple food to high-value crops [7]. Based on the Kuhn-Tucker conditions for the problem in Equation (1), the optimal choice of farmland used to produce contract products is a function of the given parameters including human capital and the farm and farm households' socio-economic characteristics.

\subsection{Empirical Specification}

Based on the theoretical model, the shares of farm produce sold to the supermarkets and hypermarkets and other retailers are considered as the determinants of contract farming participation. Let the ith farm operator's expected profits from contract farming choice be denoted by $E_{i}\left(\pi_{i}\right)$, it is further assumed that the expected profit is a linear function of the explanatory variables,

$$
E_{i}\left(\pi_{c}\right)=\mathbf{x}_{i} \boldsymbol{\alpha}_{c}+\mathbf{s}_{i} \boldsymbol{\theta}_{c}+\varepsilon_{i c}, c=0,1
$$

Here $\mathrm{c}=1$ denotes the choice of contract farming, and $\mathrm{c}=0$ otherwise. The adoption of contract farming is determined by farm operators and farm households' socio-economic characteristics $\left(\mathbf{x}_{i}\right)$, the shares of farm produce sold to the marketing options including hypermarkets/supermarkets, other retailers, and farmer organizations and government, which is denoted by vector $\mathbf{s}_{i}$.

The farm operator will choose to participate in contract farming if

$$
E_{i}(\pi(\text { Contract }=1))>E_{i}(\pi(\text { Contract }=0))
$$

where the adoption of contract farming is denoted by an indicator variable, Contract ${ }_{i}$. The probability that the choice of contract farming is made can then be expressed as

$$
\begin{aligned}
\operatorname{Prob}\left[\text { Contract }_{i}=1 \mid \mathbf{x}_{i}, \mathbf{s}_{i}\right] & =\operatorname{Prob}\left[\left(\left(\mathbf{x}_{i} \boldsymbol{\alpha}_{1}+\mathbf{s}_{i} \theta_{1}+\varepsilon_{i 1}\right)-\left(\mathbf{x}_{i} \boldsymbol{\alpha}_{0}+\mathbf{s}_{i} \theta_{0}+\varepsilon_{i 0}\right)\right)>0 \mid \mathbf{x}_{i}\right] \\
& =\operatorname{Prob}\left[\left(\mathbf{x}_{i} \boldsymbol{\alpha}+\mathbf{s}_{i} \theta+\varepsilon_{i}\right)>0 \mid \mathbf{x}_{i}\right]
\end{aligned}
$$

The random disturbance in (4) is denoted as $\varepsilon_{i}$. Taking into account the possible problem of selection bias resulting from correlation of the marketing share decisions with the disturbance term in the contract farming determination equation, Equation (4) is estimated simultaneously with the share determination equations in the following structural equation system:

$$
\begin{aligned}
& \text { Contract }_{i}^{*}=\mathbf{x}_{i} \boldsymbol{\alpha}+\mathbf{s}_{i} \boldsymbol{\theta}+\varepsilon_{i} \\
& \mathbf{s}_{i}=\mathbf{z}_{i} \kappa+u_{i} \\
& \text { Contract }_{i}=\left\{\begin{array}{l}
1 \text { if } \mathbf{x}_{i} \boldsymbol{\alpha}+\mathbf{s}_{i} \boldsymbol{\theta}+\varepsilon_{i}>0 \text { (participating in contract farming) } \\
0 \text { if } \mathbf{x}_{i} \boldsymbol{\alpha}+\mathbf{s}_{i} \boldsymbol{\theta}+\varepsilon_{i} \leq 0 \text { (otherwise) }
\end{array}\right.
\end{aligned}
$$

The full information maximum likelihood (FIML) estimates of (5) can be obtained through the following likelihood function:

$$
\begin{aligned}
& L=\prod_{i \in\left\{\text { Contract }_{i}=1\right\}} f\left(\text { Contract }_{i}, \mathbf{s}_{i}\right) \cdot \prod_{i \in\left\{\text { Contract }_{i}=0\right\}} \int_{-\infty}^{0} f\left(\text { Contract }_{i}^{*}, \mathbf{s}_{i}\right) \text { dContract }_{i}^{*} . \\
& \text { where }\left(\varepsilon_{i}, u_{i}\right) \underset{\text { iid }}{\sim} N(0, \Sigma)
\end{aligned}
$$

Based on the above specification, a further endogeneity test of the three marketing options in the contract farming determination equation can be performed. 


\section{Results}

Before proceeding with the econometric analysis of the relationship between organized retailing and contract farming, this study first performs a chi-square test against the independence between contract farming and organized retailing. The chi-square test statistic is 17.107 ( $p$-value $<0.0001)$, indicating the association between the choice of organized retailing with contract farming.

Table 2 reports the FIML estimates of the determining equations of contract farming and the three marketing options-supermarkets/hypermarkets, other retailers and government and farmer organizations. The determinants of the contract farming decision include the shares of the marketing options while controlling for the socio-economic characteristics.

Table 2. Full information maximum likelihood (FIML) estimates of contracting farming and the three marketing options.

\begin{tabular}{|c|c|c|c|c|c|c|c|c|c|c|c|c|}
\hline \multirow{2}{*}{ Variable } & \multicolumn{3}{|c|}{ M1 } & \multicolumn{3}{|c|}{ M2 } & \multicolumn{3}{|c|}{ M3 } & \multicolumn{3}{|c|}{ M4 } \\
\hline & Est. & & S.E. & Est. & & S.E. & Est. & & S.E. & Est. & & S.E. \\
\hline Intercept & -1.418 & & 1.39 & 1.954 & & 1.29 & 0.260 & & 0.83 & 2.26 & & 3.12 \\
\hline Super/hyper markets & -0.032 & & 0.24 & & & & & & & & & \\
\hline Other retailers & -0.009 & & 0.46 & & & & & & & & & \\
\hline Govt and farmer org & 0.001 & & 0.04 & & & & & & & & & \\
\hline Gender & 0.103 & & 0.26 & -1.045 & $* *$ & 0.50 & -0.038 & & 0.23 & -1.114 & & 1.00 \\
\hline Elder & -0.113 & & 0.18 & 0.064 & $* * *$ & 0.02 & 0.002 & & 0.02 & 0.027 & & 0.05 \\
\hline Farm experience & 0.006 & & 0.01 & -0.043 & $* *$ & 0.02 & 0.002 & & 0.01 & -0.042 & & 0.04 \\
\hline Junior high & 0.060 & & 0.09 & 0.151 & & 0.35 & -0.052 & & 0.19 & 0.417 & & 0.97 \\
\hline Senior high & 0.142 & * & 0.08 & 0.564 & & 0.40 & 0.006 & & 0.23 & 0.194 & & 1.11 \\
\hline College and up & -0.092 & & 0.20 & 0.614 & & 0.63 & 0.491 & & 0.39 & 0.165 & & 2.95 \\
\hline Agriculture & -0.172 & & 0.15 & -0.223 & & 0.46 & 0.031 & & 0.27 & -0.981 & & 1.24 \\
\hline Non-agriculture & 0.288 & $* * *$ & 0.10 & -0.376 & & 0.35 & -0.022 & & 0.16 & -2.268 & $* * *$ & 0.70 \\
\hline Self-employed & 0.074 & & 0.40 & 0.853 & & 0.55 & -0.138 & & 0.18 & -2.826 & $* * *$ & 0.95 \\
\hline On-farm work days & 0.002 & $* *$ & 0.00 & 0.000 & $* * *$ & 0.00 & 0.000 & $* * *$ & 0.00 & 0.000 & $* * *$ & 0.00 \\
\hline PROD-MKTG team & 0.083 & & 0.36 & -0.538 & $*$ & 0.33 & -0.096 & & 0.17 & 5.755 & $* * *$ & 0.70 \\
\hline Cooperatives & -0.330 & & 0.50 & -1.515 & $* * *$ & 0.44 & -0.022 & & 0.19 & 5.472 & $* * *$ & 1.37 \\
\hline Farmers' association & -0.026 & & 0.13 & -0.309 & & 0.42 & -0.353 & & 0.23 & 2.154 & $* * *$ & 0.69 \\
\hline Total labor & 0.023 & $* * *$ & 0.01 & 0.057 & $* *$ & 0.03 & 0.007 & & 0.01 & 0.019 & * & 0.05 \\
\hline Farm land & 0.006 & & 0.07 & -0.276 & $* * *$ & 0.10 & -0.006 & & 0.04 & -0.004 & & 0.28 \\
\hline Livestock & 0.720 & * & 0.41 & 2.060 & $* *$ & 0.96 & 0.009 & & 0.13 & -1.957 & $* *$ & 1.09 \\
\hline Processor & -0.412 & $* *$ & 0.19 & -1.097 & $* * *$ & 0.36 & -0.041 & & 0.15 & -2.182 & $* * *$ & 0.99 \\
\hline Leisure farm & -0.207 & & 0.30 & -2.081 & $* * *$ & 0.60 & -0.218 & & 0.26 & -7.711 & $* * *$ & 1.11 \\
\hline Rice & 0.141 & & 1.65 & -2.769 & $* * *$ & 0.59 & -0.081 & & 0.11 & 24.36 & $* * *$ & 1.52 \\
\hline Vegetable & -0.445 & & 1.02 & -2.138 & $* * *$ & 0.61 & 0.671 & $* * *$ & 0.17 & 9.14 & $* *$ & 1.20 \\
\hline Fruit & -0.724 & $* * *$ & 0.23 & -0.353 & & 0.64 & 0.416 & $* * *$ & 0.14 & 2.433 & $* *$ & 1.10 \\
\hline Specialty & -1.134 & $* * *$ & 0.29 & -2.589 & $* * *$ & 0.67 & -0.153 & & 0.11 & -3.149 & & 1.23 \\
\hline North & -1.047 & $* * *$ & 0.34 & & & & & & & & & \\
\hline Central & -1.168 & $* * *$ & 0.36 & & & & & & & & & \\
\hline South & -0.999 & $* * *$ & 0.33 & & & & & & & & & \\
\hline _Rho.M2.M3 & 0.000 & & 0.01 & & & & & & & & & \\
\hline _Rho.M2.M4 & -0.037 & $* * *$ & 0.00 & & & & & & & & & \\
\hline _Rho.M3.M4 & -0.021 & $* * *$ & 0.00 & & & & & & & & & \\
\hline _Rho.M1.M2 & 0.171 & & 2.87 & & & & & & & & & \\
\hline _Rho.M1.M3 & 0.093 & & 2.68 & & & & & & & & & \\
\hline _Rho.M1.M4 & -0.002 & & 1.19 & & & & & & & & & \\
\hline
\end{tabular}

The correlation coefficients reported in the last six rows of Table 2 are the correlations between the sample residuals of the four equations. Specifically, M1, M2, M3, and M4 stand for, respectively, the determination equations of contract farming, other retailers, super/hyper markets, and government and farmer organizations. In the last three rows, the correlation coefficients are not statistically significant, indicating that the sample residuals in the contract farming equation are not correlated with the residuals in the three marketing options. Therefore, a further endogeneity test of the three marketing options in the contract farming determination equation was performed. The null hypothesis of the endogeneity test maintains that the correlations between sample residuals of contract farming and the three marketing options are zero, i.e., $\rho_{M 1 . M 2}=0, \rho_{M 1 . M 3}=0$ and $\rho_{M 1 . M 4}=0$. The Wald 
chi-square statistic of endogeneity test is 5.530 ( $p$-value $=0.137)$, indicating that there is no reason to reject the exogeneity of the three marketing options in the determination of contract farming. Accordingly, a standard probit model is estimated and reported in Table 3.

Table 3. Probit estimates and marginal effects on contract farming participation.

\begin{tabular}{|c|c|c|c|c|}
\hline Variable & Estimate & & S.E. & M.E. \\
\hline Intercept & -1.2064 & $* * *$ & 0.289 & \\
\hline Other retailers & -0.0176 & $*$ & 0.010 & -0.0012 \\
\hline Super/Hyper markets & 0.0069 & $* *$ & 0.003 & 0.0005 \\
\hline Govt and farmer org & 0.0013 & & 0.001 & 0.0001 \\
\hline Gender & 0.1369 & & 0.095 & 0.0096 \\
\hline Elder & -0.0075 & * & 0.004 & -0.0005 \\
\hline Farm experience & 0.0089 & $* * *$ & 0.003 & 0.0006 \\
\hline Junior high & 0.0482 & & 0.081 & 0.0034 \\
\hline Senior high & 0.1014 & & 0.087 & 0.0071 \\
\hline College and up & -0.1495 & & 0.131 & -0.0105 \\
\hline Agriculture & -0.1860 & & 0.145 & -0.0131 \\
\hline Non-agriculture & 0.3119 & $* * *$ & 0.066 & 0.0219 \\
\hline Self-employed & 0.0811 & & 0.107 & 0.0057 \\
\hline On-farm work days & 0.0017 & $* * *$ & $<0.001$ & 0.0001 \\
\hline PROD-MKTG team & 0.0949 & $* * *$ & 0.058 & 0.0067 \\
\hline Agri. cooperatives & -0.3262 & $* * *$ & 0.119 & -0.0229 \\
\hline Farmers' association & -0.0164 & & 0.077 & -0.0012 \\
\hline Total labor & 0.0217 & $* * *$ & 0.006 & 0.0015 \\
\hline Farm land & 0.0105 & & 0.024 & 0.0007 \\
\hline Livestock & 0.7147 & $* * *$ & 0.102 & 0.0502 \\
\hline Processor & -0.3933 & $* *$ & 0.164 & -0.0276 \\
\hline Leisure farm & -0.2181 & & 0.251 & -0.0153 \\
\hline Rice & 0.1876 & * & 0.110 & 0.0132 \\
\hline Vegetable & -0.4324 & $* * *$ & 0.102 & -0.0303 \\
\hline Fruit & -0.7344 & $* * *$ & 0.106 & -0.0515 \\
\hline Specialty & -1.0635 & $* * *$ & 0.216 & -0.0746 \\
\hline North & -1.071 & $* * *$ & 0.105 & -0.0752 \\
\hline Central & -1.1843 & $* * *$ & 0.078 & -0.0831 \\
\hline South & -1.0034 & $* * *$ & 0.080 & -0.0704 \\
\hline
\end{tabular}

Note. ${ }^{*}, * *, * * *$ denote significant at $10 \%, 5 \%$, and $1 \%$ significance level.

\section{Discussion}

\subsection{Determining Factors of Contract Farming}

Results in Table 3 report the probit estimates of the contract farming equation. The results indicate that selling farm produce to supermarkets and/or hypermarkets increases the probability of contract farming. This result confirms the conjecture in the literature of contract farming that a consolidation in retail food outlets through the supermarket and/or hypermarkets is one of the factors contributing to the prevalence of contract farming $[4,17,18]$. It was indicated that pesticide residue is the major concern to the supermarkets, and supermarkets tend to contract with the farmers in order to meet the quality and safety standards of their consumers [4]. Similarly, the rise in the share of sales to food retails accounted for by supermarkets was stressed to be an appropriate indicator for the proportion of transactions undertaken through contract arrangement [28].

However, the choice of other retailers for marketing channels including convenience stores, local grocers, and chain stores exhibits a negative effect on the probability of participating in contract farming. Among the three marketing options, sales to local grocery stores, chain stores, and convenience stores usually involve direct store deliveries, that is, these retailers are mostly inclined to buy directly from growers through direct store deliveries [29]. The reliance of these retailers on the direct store deliveries 
may explain why farm households selling farm produce to these retailers have a lower probability of contract farming participation.

Although the results in Table 3 indicate the differential influence of each socio-economic factors, most of the results are in general consistent with previous research on the determinants of contract farming participation. Results in Table 3 indicate that male and younger farm operators are more inclined to participate in contract farming. There are two human capital related predictors considered in this study. One is the farm operator's farming experience, the other is the level of education. Only the former is found to contribute positively to the probability of participation. However, this result is consistent with previous studies finding farmers with higher levels of human capital tend to have a higher probability to participate in formal contracts.

The influence of the industry the farm operator worked prior to entering the farm business reveal some interesting results. Results in Table 3 indicate that for those previously employed by agriculture or self-employed, the probability of participating in contract farming is not significantly different from the farm operators who were unemployed prior to entering farm business. The coefficient for the farm operators previously worked in business and manufacturing/service industries is positive and significant, indicating the farm operators previously worked in nonfarm industries are more likely to participate in contract farming. The other two variables involving the farm operator's characteristics are days of on-farm work (on an annual base) and his/her membership of farmer organizations which include farmers' associations, agricultural cooperatives, and production-marketing teams. The results indicate that farm operators who devote more time to on-farm work or partnership with local farmers producing the same type of farm produce are more inclined to contracting with food retailers.

There are four types of farm household characteristics considered in the present study, which include farm household's total labor input (own- and hired-labor), size of farm land, types of operation, and the geographical location of the farm household. Although the results in Table 3 indicate the positive effect of the farm household's total labor input on the probability of choosing contract farming, the size of farmland was not found to be a significant determinant for the choice of contract farming. Farm households with livestock as the operation type is found to have a higher probability of contract farming participation among all operation types. Moreover, rice growers are more likely to participate in contract farming compared with other-crop farm households. The effect of geographical locations is found to be unanimous. The significant and negative coefficients for north, central, and south areas indicate that farm households located in eastern Taiwan are most likely to participate in contract farming.

\subsection{Further Analysis of the Inclusiveness of Contract Farming}

A common finding in the literature of contracting farming is the retailers' preferences over larger producers. In order to address the issue concerning if contract farming in Taiwan is inclusive of the smallholders, the households with zero hectare of farmland is excluded in the following analysis. The further analysis of the inclusiveness of contract farming is based on the categorization rule in PFHS. Since in most previous studies, the inclusiveness of contract farming is based on delineating the relationship between contract farming participation and landholding or farmland size, a comparison of the two categorization rules is performed before examining the contracting firm's scale bias. Due to the fact that the majority of farms in Taiwan is small in size with an average of farmland less than 1 hectare, the medium and the 75th percentile of farmland is used as the criterion to categorize the farm households into three groups-small, medium, and large scales. On the other hand, in the PFHS, the size of the farm households is categorized by annual farm income into three groups: large (income $>=\$ 60,000)$, medium $(\$ 23,333<=$ income $<\$ 60,000$ ) and small (income $<\$ 23,333$ ). The PFHS categorization rule basically concurs with that based on farmland size since the chi-square test of the independence of the household categorized through the PFSH and the farmland-size criterions is soundly rejected with a chi-square statistic of 439.8765 ( $p$-value $<0.001$ ). 
In order to investigate if the empirical results support the common finding of contracting firms' preferences over medium- and large-scale growers in the literature, a robust regression analysis is used to test for the mean differences in the probability of contract farming participation among the three groups of farm households. There are basically two models considered, model I regresses the predicted probability of contract farming on the two dummy variables with one indicating medium-scale households and the other large-scale households. Model II includes the interaction terms of farmer organization participation and production-scale dummy variables. Models I and II in Table 4 are results from the robust regression with farm households categorized into three groups according to the PFHS criterion. Before the moderating effect of farmer organization membership is considered, the results in model I illustrate contracting firms' preferences over the medium- and large-scale farm households since small households' predicted probability is significantly lower than either the medium or large growers. Considering the possible moderating effect of farmer organization participation [9], model II includes the interaction terms of farm size and the membership of at least one of the farmer organizations. The coefficient of the interaction term of farm size and farmer organization membership are both negative indicating the participation of farmer organizations can reduce the scale bias. This result is consistent with the transaction-cost or entry-barrier reducing effect of the agricultural cooperatives that was found in previous studies $[9,11]$, which suggests participation in farmer organizations can help alleviate the contracting firm's bias towards medium or large producers.

Table 4. Mean regression of participation probability on size and membership.

\begin{tabular}{|c|c|c|c|c|c|c|c|c|}
\hline \multirow{2}{*}{ Variable } & Robust Coef. & & Std. Error & $p$-Value & Robust Coef. & & Std. Error & $p$-Value \\
\hline & \multicolumn{4}{|c|}{ Model I } & \multicolumn{4}{|c|}{ Model II } \\
\hline Medium_scale & 0.0068 & $* * *$ & 0.0014 & $<0.001$ & 0.0161 & $* * *$ & 0.0048 & 0.001 \\
\hline Large_scale & 0.0451 & $* * *$ & 0.0032 & $<0.001$ & 0.0563 & $* * *$ & 0.0122 & $<0.001$ \\
\hline Medium * Member & & & & & -0.0099 & $* *$ & 0.0049 & 0.043 \\
\hline Large * Member & & & & & -0.0120 & & 0.0126 & 0.341 \\
\hline
\end{tabular}

Note: ${ }^{*}, * *, * * *$ denote significant at $10 \%, 5 \%$, and $1 \%$ significance level.

In order to obtain a more comprehensive delineation of the moderating role of farmer organization participation in the relationship between contract farming and production scale, the quantile regression is used to find the coefficient of the size dummy variables and/or the interaction terms in model II. Figure 2 presents the results for quantile regression of model II with $95 \%$ confidence interval. Most of the coefficient estimates of the two size dummy variables in each probability decile are positive and significant. In comparison, the coefficient of the large-scale indicators is greater than the medium-scale ones. Moreover, although the coefficients of the interaction terms of production scale and farmer organization membership are both negative in all deciles, only the coefficients in the higher deciles are significant. The result therefore suggests that the moderating effect of farmer organization participation is stronger among the top deciles. 

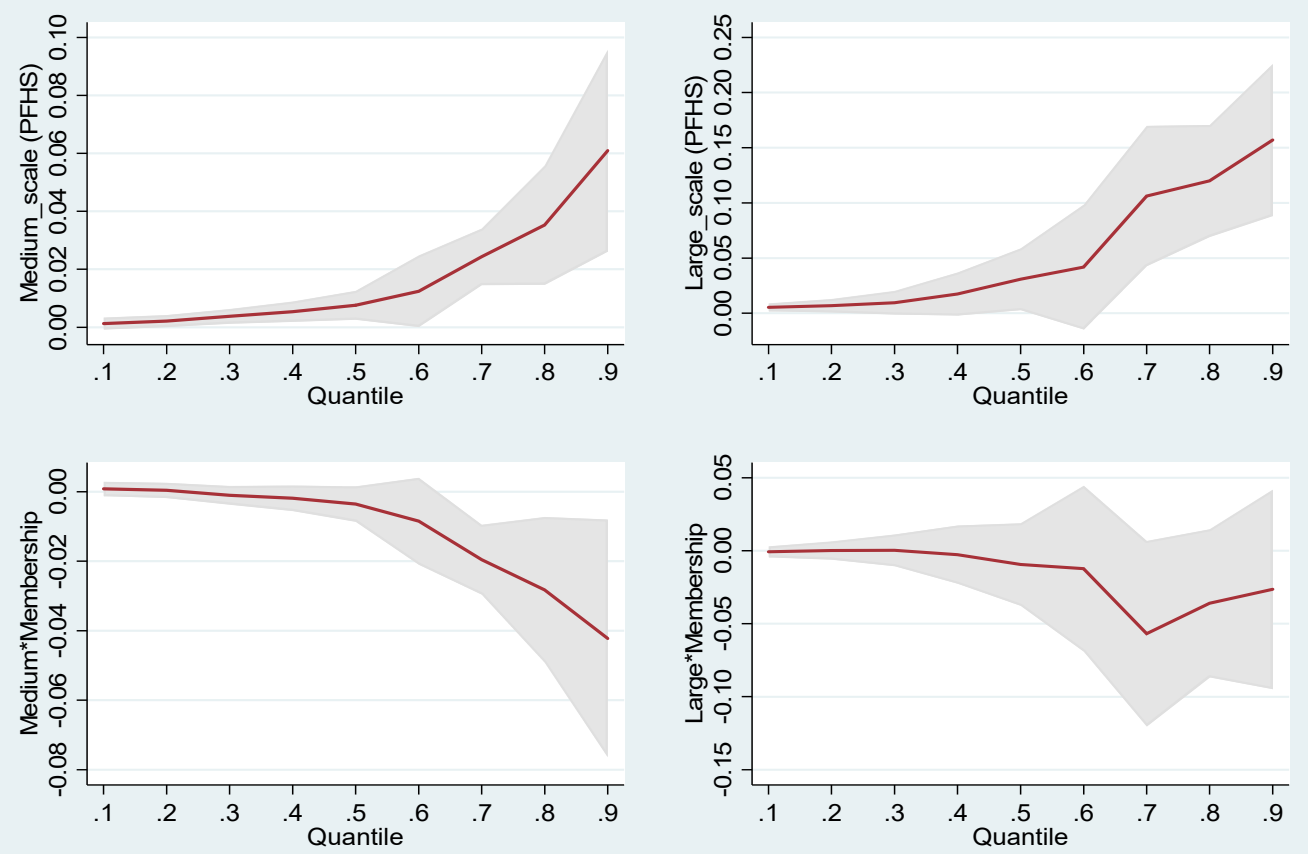

Figure 2. Quantile regression, farm size categorized by Primary Farm Household Survey (PFHS) criterion.

\section{Conclusions}

One of the debates in the literature of contract farming concerns contracting firms' preferences over large growers and if contract farming is inclusive of smallholders. The empirical evidence was mixed, which this study argues that may be due to ignoring the stylized fact that large organized retailers often contract with farmers. Based on a nationally representative data set, the empirical results provide evidence to support the effects of organized retailing on smallholder farm's participation in contract farming while controlling for the socio-economic characteristics of the farm, household and principal operators. It is found that increase in the share of selling farm produce to supermarkets and hypermarkets leads to higher probability of contract farming. However, the increase in the share of chain stores, convenience stores, as well as local grocers lowers the probability of contract farming participation.

Most of the previous studies on the inclusiveness of contract farming is based on the association of contract farming participation and landholding or farmland size. Using the farm household size categorization rule in the PFHS, this study categorizes the farm households into three groups to investigate if the empirical results support the common finding of contracting firms' preferences over medium- and large-scale growers in the literature. The results illustrate that the contracting firms in Taiwan prefer medium- and large-scale farm households to their small-scale counterparts. A further analysis considering the possible moderating effect of farmer organization participation indicates that the participation of farmer organizations can significantly reduce the contracting firms' scale bias. The result therefore provides empirical evidence to support the transaction-cost or entry-barrier reducing effect of the agricultural cooperatives found in previous studies. Moreover, it is found that the moderating effect of farmer organization participation is stronger among the top deciles, suggesting this moderating effect is more pronounced among those more inclined to participate in contract farming.

Two important policy implications can be inferred from the present study. First of all, Taiwan has been implementing the "Specialized Crop Production-Distribution Area" policy for more than one decade. One of the major aims of the policy is to encourage contracting farming to improve 
smallholder income. Since participation in farmer organization is found to help alleviate the contracting firms' preferences over the medium- or large-scale growers, in order for the "Specialized Crop Production-Distribution Area" policy to achieve the policy agenda of improving smallholder income through contract farming, more incentives to promote the participation of the farmer organizations need to be provided to the smallholders. The second policy implication concerns the verified association between contract farming and organized retailers. The results in this study suggest the effect of organized retailing on contract farming participation varies with different types of food retailers. Taking this differential effect into consideration is thus crucial for designing farm programs targeting at enhancing vertical coordination in the modern food supply chain.

Funding: Part of this research was funded by the Ministry of Technology and Science (MOST) in Taiwan, grant number: MOST-106-2410-H-002-018.

Conflicts of Interest: The author declares no conflict of interest.

\section{References}

1. Glover, D.J. Contract farming and smallholder out grower schemes in less-developed countries. World Dev. 1984, 12, 1143-1157. [CrossRef]

2. Singh, S. Contracting out solutions: Political economy of contract farming in the Indian Punjab. World Dev. 2002, 30, 1621-1638. [CrossRef]

3. Costales, A.; Son, N.T.; Lapar, M.L.; Tiongco, M. Determinants of Participation in Contract Farming in Pig Production in Northern Vietnam. In FAO-PPLPI Research Report 08-04; Food and Agriculture Organization: Rome, Italy, 2008.

4. Miyata, S.; Minot, N.; Hu, D. Impact of contract farming on income: Linking small farmers, packers, and supermarkets in China. World Dev. 2009, 37, 1781-1790. [CrossRef]

5. Swain, B.B. Determinants of farmers' participation in contract farming: The cases of gherkin and paddy seed in Andhra Pradesh, India. Millenn. Asia 2012, 3, 169-185. [CrossRef]

6. Freguin-Gresh, S.; Anseeuw, W.; D'Haese, M. Demythifying contract farming: Evidence from rural South Africa. Agric. Econ. Res. Policy Pract. South. Afr. 2012, 51, 24-51. [CrossRef]

7. Minot, N.; Ronchi, L. Contract Farming: Risks and Benefits of Partnership between Farmers and Firms; Viewpoint: Public Policy For The Private Sector No. 344; World Bank: Washington, DC, USA, 2014.

8. Azumah, S.B.; Donkoh, S.A.; Ehiakpor, D.S. Examining the determinants and effects of contract farming on farm income in the northern region of Ghana. Ghana J. Sci. Technol. Dev. 2016, 4, 1-10.

9. Ba, H.A.; de-Mey, Y.; Thoron, S.; Demont, M. Inclusiveness of contract farming along the vertical coordination continuum: Evidence from the Vietnamese rice sector. Land Use Policy 2019, 87, 104050. [CrossRef]

10. Simmons, P.; Winters, P.; Patrick, I. An analysis of contract farming in East Java, Bali, and Lombok, Indonesia. Agric. Econ. 2015, 33, 513-525. [CrossRef]

11. Key, N.; Runsten, D. Contract farming, smallholders, and rural development in Latin America: The organization of agroprocessing firms and the scale of outgrower production. World Dev. 1999, 27, 381-401. [CrossRef]

12. Bijman, J. Contract farming in developing countries: An overview. In Working Paper; Wageningen University, Department of Business Administration: Gelderland, the Netherlands, 2008.

13. Guo, H.; Jolly, R.W.; Zhu, J. Contract Farming in China: Supply Chain or Ball and Chain? Department of Agricultural Economics, Zhejiang University: Zhejiang, China, 2005.

14. Birthal, P.S.; Joshi, P.K.; Gulati, A. Vertical coordination in high-value food. In MTID Discussion Paper No. 85; International Food Policy Research Institute: Washington, DC, USA, 2005.

15. Swain, B.B. Determinant in intensity of farmers' participation in contract farming: The study of gherkin and hybrid paddy seed cultivation in a south Indian state. J. Land Rural Stud. 2018, 6, 170-190. [CrossRef]

16. Eaton, C.; Shepherd, A. Contract Farming: Partnerships for Growth; Food and Agriculture Organization of the United Nations: Rome, Italy, 2001.

17. Royer, J.S.; Rogers, R.T. (Eds.) The Industrialization of Agriculture: Vertical Coordination in the U.S. Food System; Ashgate Publishing: Brookfield, UK, 1998. 
18. Ochieng, D.O.; Veettil, P.C.; Qaim, M. Farmers' preferences for supermarket contracts in Kenya. Food Policy 2017, 68, 100-111. [CrossRef]

19. Atalaysun, M. Turkey Retail Foods; GAIN Report TR6057; USDA Foreign Agricultural Service: Washington, DC, USA, 2016.

20. Rangkuti, F.Y.; Wright, T. Indonesia Retail Foods; GAIN Report ID1358; USDA Foreign Agricultural Service: Washington, DC, USA, 2013.

21. Bhatnagar, S. Challenges and success mantras for unorganised retailing against organised retailing. Int. J. Manag. MIT Coll. Manag. 2015, 3, 33-36.

22. Negi, S.; Anand, N. An Overview of Fruits and Vegetables' Retail Supply Chain Models in India. In Handbook of Research on Strategic Supply Chain Management in the Retail Industry; Kamath, N., Saurav, S., Eds.; IGI Global: Hershey, PA, USA, 2016; pp. 170-187.

23. Rao, N.C.; Radhakrishna, R.; Mishra, R.K.; Kata, V.R. Implications of New Supply Chains on the Indian Farm Economy: An Overview. In Organised Retailing and Agri-Business: Implications of New Supply Chains on the Indian Farm Economy; Rao, N.C., Radhakrishna, R., Mishra, R.K., Kata, V.R., Eds.; Springer: New Delhi, India, 2016; pp. 1-25.

24. Genius, M.; Pantzios, C.J.; Tzouvelekas, V. Information acquisition and adoption of organic farming practices. J. Agric. Resour. Econ. 2006, 31, 93-113.

25. Seo, S.N.; Mendelsohn, R. Animal husbandry in Africa: Climate change impacts and adaptations. Afr. J. Agric. Resour. Econ. 2008, 2, 65-82.

26. Kurukulasuriya, P.; Mendelsohn, R. Crop switching as a strategy for adapting to climate change. Afr. J. Agric. Resour. Econ. 2008, 2, 105-125.

27. Luh, Y.-H.; Tsai, M.-H.; Fang, C.-L. Do first-movers in the organic market stand to gain? Implications for promoting cleaner production alternatives. J. Clean. Prod. 2020, 262, 121156. [CrossRef]

28. Blandon, J.; Henson, S.; Cranfield, J. Small-scale farmer participation in new agri-food supply chains: Case of the supermarket supply chain for fruit and vegetables in Honduras. J. Int. Dev. 2009, 21, 971-984. [CrossRef]

29. Rowell, B.; Woods, T.; Mansfield, J. Marketing Options for Commercial Vegetable Growers; Cooperative Extension ID-134; College of Agriculture, University of Kentucky: Stanford, KY, USA, 1999.

(C) 2020 by the author. Licensee MDPI, Basel, Switzerland. This article is an open access article distributed under the terms and conditions of the Creative Commons Attribution (CC BY) license (http://creativecommons.org/licenses/by/4.0/). 